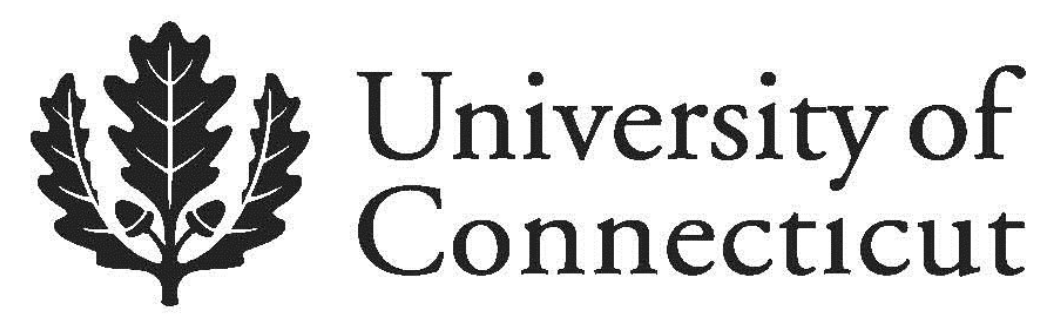

Department of Economics Working Paper Series

\title{
Project Selection: Commitment and Competition
}

Vidya Atal

Montclair State University

Talia Bar

University of Connecticut

Sidhartha Gordon

Sciences Po

Working Paper 2014-28

July 2014

365 Fairfield Way, Unit 1063

Storrs, CT 06269-1063

Phone: (860) 486-3022

Fax: (860) 486-4463

http://www.econ.uconn.edu/

This working paper is indexed on RePEc, http://repec.org 


\title{
Project Selection: Commitment and Competition*
}

\author{
Vidya Atal’ Talia Barªnd Sidartha Gordon ${ }^{\ddagger}$
}

July 26, 2014

\begin{abstract}
We examine project selection decisions of firms constrained in the number of projects they can handle at once. Taking on a project requires a commitment of uncertain duration, restricting the firm from selecting another project in subsequent periods. Due to the capacity constraints and need for commitment, some positive return projects are rejected. In a sequential move dynamic game, we find that the first mover strategically rejects some projects that are then selected by the second mover, even when both firms are symmetric and equally informed. We study the effects of competition on project selection, and compare the jointly optimal selection decision to the behavior of strategic non-cooperative firms.
\end{abstract}

Keywords: project selection, search, commitment, Markov perfect equilibrium JEL Classification Codes: L10, L13, D21.

${ }^{*}$ We are grateful to Haim Bar, Dirk Bergemann and Emeric Henry for detailed comments and helpful advice and to Tal Cohen for insightful conversations. We also thank various seminar attendees, and conference participants at the 6th Israeli Game Theory Conference and the 25th International Conference on Game Theory for their comments and suggestions.

${ }^{\dagger}$ Department of Economics and Finance, Montclair State University. 1 Normal Avenue, Partridge Hall 427, Montclair, NJ 07043; email: atalv@mail.montclair.edu.

${ }^{\ddagger}$ Department of Economics, University of Connecticut. 365 Fairfield Way, Oak Hall Room 335, Storrs, CT 06269; e-mail: talia.bar@uconn.edu.

${ }^{\S}$ Department of Economics, Sciences Po, 28 rue des Saints-Pères, 75007 Paris, France; email: sidartha.gordon@sciences-po.org. 


\section{Introduction}

Firms as well as researchers and government agencies repeatedly select projects (e.g., research and development projects, clients to serve, acquisition of start-ups, and new products). In many situations, the firms are constrained in the number of projects they can work on at once. If a firm takes on a project, it may last for a number of periods, during which the firm's resources (e.g., researchers' and other employees' time, physical space, lab equipment) are committed. Firms' project selection decisions are made under uncertainty about the duration of the project being considered and about the value of future project opportunities. Committing limited resources to one project may result in the need to forgo future, perhaps more profitable, projects.

Firms' project selection decisions are often taken in strategic environments. When firms search in a common pool, one firm's decision to select a project can affect its rival's opportunities, at present, because this project is no longer available, and in the future, because the firm commits its resources. Additionally, when a firm takes on a project, it not only affects its own payoffs, but may also create payoff externalities.

In our model, two firms play a dynamic, infinite horizon game. Every period a new project opportunity arises. The expected return of each project is randomly drawn from a given distribution. Firms learn the expected return of the current project, and know the distribution from which future project returns are drawn. A project has random duration. We assume that for a firm that is currently committed, there is a fixed probability that the project will end by the next period. Each period, if one of the firms is committed and the other is free, the free firm can select the project or reject it. If both firms are free, one firm is chosen at random to be that period's leader - the first firm to consider the project. If the period's leader rejects the project, then the period's follower can consider selecting it. Sequential project selection decisions occur in some markets. For example, pharmaceutical companies repeatedly face project opportunities presented by small biotech firms who negotiate with the pharmaceutical companies sequentially ${ }^{1}$ Service providers

\footnotetext{
${ }^{1}$ See, for example, Kolchinsky (2004) on page 56 on negotiation agreements, and http://www.secinfo.com/d12MGs.1n4.htm on a news release describing Micrologixs Biotech Inc. entering an exclusive negotiation period with a pharmaceutical company.
} 
(e.g., consulting firms, contingent fee lawyers, contractors) are sequentially approached by clients, and need to decide whether to take the client knowing that accepting to serve him requires commitment, and rejecting may bring him to a rival firm.

If projects did not require commitment, in a symmetric game, a leader would take on any project with a positive return, and a follower would never take on any project. But, since projects can last longer than one period, and require commitment of resources, positive return projects may be rejected by both firms. A leader selects projects that have high enough returns. Interestingly, when projects require commitment, we show that there are projects with intermediate levels of return that are rejected by the period's leader, yet selected by the follower. This is true even though both firms are identical, expect the same future opportunities and have the same information about the value of the current project. Intuitively, a follower still wants to take on an intermediate value project because its return is sufficiently high, and if he rejects it, no one will take on this project. But the leader prefers to reject the intermediate value project knowing that the follower will select it, as the leader can enjoy less competition in the following period when a more profitable project may arise.

To examine the effects of competition on project selection behavior, we compare the outcome of the game to two benchmarks: a decision maker with a capacity of one project, and a decision maker with a two-project capacity. The first of these problems is similar to existing sequential search models, and is included for comparison with the strategic situation. We find that project selection thresholds are lower under competition. That is, a duopolist selects projects that it would have rejected absent a competitor in the market. One intuition for this is that the duopolist expects to face an inferior selection of projects, as some high value projects will be adopted by his rival. We also compare equilibrium selection to the optimal choice of a joint venture (maximizing sum of profits with a two-project capacity). We find that in duopoly competition, firms reject too many projects compared to the jointly optimal behavior. Intuitively, the joint venture is less concerned about commitment, as it has a two projects capacity, and a joint venture eliminates the duopolist's strategic incentive to keep a rival busy.

Our main model assumes that the leader in each period is chosen at random. This assumption is natural when firms are symmetric. It illustrates the incentive to keep a rival 
busy, in a setting where it seems most surprising that one firm would accept a project rejected by the other. However, in some cases, one of the firms may have an advantage (perhaps it is better known, or more easily accessible). We study a version of the game in which one firm is the leader in every period. In this asymmetric game, the follower will be less selective than the leader for an additional reason: project opportunities for the follower arise from an inferior (right censored) distribution of project returns, because when free, the leader selects the most promising projects.

The rest of this paper proceeds as follows. In Section 2, we discuss related literature. In Section 3, we describe the basic model with a single decision maker. Section 4 develops the game and analyzes the strategic interaction between two firms. In Section 5, we analyze the dominant firm version. Section 6 concludes.

\section{Related Literature}

Our paper is related to a few distinct bodies of literature: sequential search, particularly, models of strategic interaction between a small number of searching agents, queueing theory in operations research, and a literature on project selection. We describe some of the existing literature and our contribution.

Our analysis of a single decision maker is closely related to labor search models. In early job search models (e.g., McCall, 1970; Mortensen, 1970), workers cannot search for a job while employed, and staying employed is better than becoming unemployed. In Burdett and Mortensen (1998) and Postel-Vinay and Robin (2002), workers continue searching for better jobs while employed, thus in these models there is no binding commitment. In the context of a job search, the worker obtains a flow income for the duration of employment. In contrast, we assume that the firm's expected value from a completed project is independent of the development duration. Our firm needs to commit resources until the project is complete. Then it is free to select an additional profitable project without forgoing the returns of the completed project. For example, when a consultant completes a service to a client, he is paid the agreed amount, and is then free to serve the next client. Whereas a worker fears a layoff, our firm eagerly awaits project completion. 
Our model contributes to a surprisingly small category of strategic search models in which selectivity is taken as the main strategic variable $2^{2}$ Reinganum $(1982,1983 \mathrm{a})$ considers a game where sequential search for a technology is undertaken simultaneously. Once all firms have completed their search, they compete in the goods market. The dates at which the firms stop searching play no role. Some authors offered variations and extensions to Reinganum's strategic search models (e.g., Lippman and Mamer, 1993; Taylor, 1995; Daughety and Reinganum, 2000; Hoppe, 2000).

Our model differs from the strategic search models in several important ways. In these models, the agents search in different pools. The interaction comes from the effect that the other agent's search outcome has in a subsequent stage. In contrast, in our model, the selectivity of a firm affects the distribution of projects faced by the other firm both in the same period and in subsequent periods. In our model, whether a firm is committed to a project is common knowledge, and a firm's best response depends on the current state. Additionally, our firms alternate between periods of search and periods of development. This is a common setting in job search models, but, to the best of our knowledge, it has not been analyzed in a strategic search game.

Our work is also related to a literature in operations research on queuing. In an early contribution, Lippman and Sheldon (1969) characterized the optimal strategy of a single server who faces clients with different rewards and expected service times. Queueing models typically feature servers that can serve one customer at a time. Customers randomly arrive and choose a strategy (for example to join the queue or not) to maximize their payoffsbenefits from the service minus cost of waiting. A central issue in this literature is how to reduce individual waiting time (see Hassin and Haviv, 2003). A subset of papers in this area examines strategic interactions between servers. For example, Kalai, Kamien and Rubinovitch (1992) study competition between servers on service speed. In contrast, we take the service speed as given, and focus on firms' selectivity when projects take random values

\footnotetext{
${ }^{2}$ In models of patent or R\&D races (Loury, 1979; Lee and Wilde, 1980; Reinganum, 1983b), search intensity is the main strategic variable. There is one object to be found, so that selectivity (which is central in this paper) is not an issue. Selectivity is the decision variable also in models of labor markets with many firms and workers, such as Pissarides (1985).
} 
and firms compete over the same projects. Our firms care about projects' values and payoff externalities, and not just about market shares. In our model, projects that are not selected are lost rather than placed in a queue.

In the management literature, the closest paper to ours is by Cassiman and Ueda (2006). They model the interaction between an established firm deciding whether to commercialize innovations and (sequential) startup firms. A key assumption, as in our paper, is that the firm can commercialize only a limited number of innovations. They consider a Nash bargaining solution concept while we take a non-cooperative game approach. In our model, a project has a finite uncertain duration while Cassiman and Ueda restrict to irreversible commercialization (infinite duration). This, together with their efficient allocation of projects that results from bargaining, allows them to analyze a more general capacity of $J$ innovations while we restrict to one or two projects for tractability.

Papers on capital allocation in management mostly consider the decision to finance a single project, and focus on information asymmetry (see, for example, Harris and Raviv, 1996 and Zhang, 1997). Hall and Lerner (2010) survey the literature on financing of innovation with a focus on financial market reasons for under-investment. Our assumption on firms' project capacity constraint is different from the standard capital financing constraint. Firms can be limited in the number of projects they select even if they have cash reserves, or access to venture capital..$^{3}$ Dixit and Pindyck (1994) survey work on investment under uncertainty. When firms are uncertain about the returns of (irreversible) capital investment, an opportunity to delay investment gives the firm a call option 4

\section{Basic Model}

We begin by describing the model in the context of a decision maker - a single firm that repeatedly decides whether to select projects that arise sequentially. We add strategic inter-

\footnotetext{
${ }^{3}$ Capacity constraints could arise due to a limited number of skilled scientists and engineers, limited physical space to run experiments, etc. Capacity constraints rather than budget constraints are used also in the literature on rational inattention, see Sims (2010).

${ }^{4}$ Our problem has also some similarity to the problem of dynamic assignment of a single durable object to successive agents, considered by Bloch and Houy (2012).
} 
actions between two firms in the next section.

Consider a discrete time infinite horizon model. The decision maker maximizes the discounted sum of expected payoffs. The discount factor is $0<\delta<1$. A new project opportunity arises every period. If the decision maker is not currently committed, he can decide whether to select this project. A project requires a commitment of resources, which prevents the firm from working on more than one project at a time. Binding commitments to a project can arise due to agreements with clients, employees, or suppliers, or because the firm cannot search for new opportunities while working on the current project. It is also possible that projects require a sunk cost that makes abandoning a project, even for a better one, not worthwhile.

When faced with a project opportunity, the firm is uncertain how long the project would take. To capture the random duration of projects, we assume that if a firm is committed, the commitment will end by the next period with a probability $p \in[0,1]$. For example, for a service provider, project duration can be the time it takes to complete the service; for a firm engaged in acquisitions, the time it takes to transfer knowledge from the innovator to the firm, to develop the product, and to come up with a marketing strategy.

Each project has a randomly drawn return $v$, which is the expected discounted present value of net benefits from the project at the time it is selected. We assume project returns are identically and independently drawn from a known distribution with a cumulative distribution function $F(v)$ on a finite support $[\underline{v}, \bar{v}]$, such that $\underline{v} \leq 0$, and $\bar{v}>0$. For all $v, F$ is differentiable with a finite density $f(v)>0$. The expected value of returns, $\int_{v}^{\bar{v}} v f(v) d v$, is positive. We treat the payoff $v$ as obtained immediately in order to simplify the exposition. However, given our assumption of a binding commitment to the project, the analysis is similar if the prize is obtained at the end of the commitment period (e.g., an agreed payment when a service is completed), or if flow profits start at that time (e.g., profits from launching a new product), or if a flow cost is incurred for the duration of the project's commitment. The value $v$ should be interpreted as the net expected value at the time the decision is made. The payoff in a period in which no project is selected is zero. 


\subsection{A Decision Maker's Project Selection}

Let us denote the value function in any period for which the decision maker is not committed, before realization of the project's return, by $V_{0}$. Let $V_{1}$ denote the value function for the decision maker who is committed from an earlier period.

When the decision maker is committed, he cannot select another project. Thus,

$$
V_{1}=\delta\left[p V_{0}+(1-p) V_{1}\right]
$$

When he is free, he chooses to select or not to select so as to maximize:

$$
\max \{\underbrace{v+\delta\left(p V_{0}+(1-p) V_{1}\right)}_{\text {payoff if select }}, \underbrace{\delta V_{0}}_{\text {payoff if reject }}\} .
$$

Thus, a project is selected if $v \geq v_{0}$ where:

$$
v_{0}=\delta(1-p)\left(V_{0}-V_{1}\right)
$$

The value in the state without commitment is:

$$
V_{0}=\int_{\underline{v}}^{v_{0}} \delta V_{0} f(v) d v+\int_{v_{0}}^{\bar{v}}\left[v+\delta\left(p V_{0}+(1-p) V_{1}\right)\right] f(v) d v .
$$

In a model without commitment $(p=1)$, the selection threshold would be $v_{0}=0$. But when projects require commitment $(p<1)$, some positive return projects are rejected. In Proposition 1, we examine how the unique optimal threshold changes with the parameters of the model.

Proposition 1 (i) There exists a unique solution to the system (1)-(3), with a threshold value for project selection $v_{0} \in(0, \bar{v})$. (ii) The threshold $v_{0}$ is higher when the commitment required for each project is expected to last longer (lower p); and when the decision maker is more patient (higher $\delta$ ).(iii) The threshold $v_{0}$ is at least as high for a distribution of returns that either first order stochastically dominates another or is a mean-preserving spread of another.

The return from selected projects is expected to be higher in an industry in which firms typically commit to projects that take a long time to complete. In the pharmaceutical 
industry, for example, it takes about 10 years to bring a drug to the market (see Nicholas, 1994). In terms of our model, $p$ is low in this industry. Thus we would expect higher selection thresholds compared to industries with projects of shorter commitment, as perhaps is true in the context of software development.

If project opportunities arise frequently, then the project selection threshold would be higher than for infrequent arrivals. This is because $\delta$ is higher and $p$ is lower in such situations. Hence, we would expect a decision maker who frequently faces project opportunities to select higher return projects, than a decision maker who encounters project opportunities infrequently.

The threshold for selection is higher for the dominating distribution because there is a higher probability that a better project will arise in the following periods. Intuitively, the threshold for selection is higher for the spread because the firm can enjoy the higher return project while rejecting the lower return ones.

\subsection{Two-Project Capacity Constraint}

We now consider a decision maker who can work on two projects at a time. We compare project selection of this less constrained firm to the single project capacity of the previous subsection. We also use the two-project capacity model later, when comparing a duopoly to a joint venture.

We denote the value functions of the decision maker with a two-project capacity with $W_{i}$, to distinguish from that of the single project capacity values $V_{i}$. The index $i \in\{0,1,2\}$ in $W_{i}$ refers to the number of projects to which the decision maker is committed. In state 2 , the decision maker cannot select a project. The optimal choices in states 0 and 1 are given by thresholds of selection $w_{0}$ and $w_{1}$, respectively. Similar to our analysis in the previous section, we write the system of dynamic programming equations that characterizes optimal decisions of the two-project capacity decision maker. The value in state 2 (when the firm is committed to two projects) is:

$$
W_{2}=\delta\left[p^{2} W_{0}+2 p(1-p) W_{1}+(1-p)^{2} W_{2}\right]
$$


In state 1, the threshold level satisfies:

$$
w_{1}=\delta\left(p W_{0}+(1-p) W_{1}\right)-W_{2}
$$

The value functions in state 1 is:

$$
W_{1}=\int_{w_{1}}^{\bar{v}}\left(v+W_{2}\right) f(v) d v+F\left(w_{1}\right) \delta\left(p W_{0}+(1-p) W_{1}\right) .
$$

In state 0 , the threshold level satisfies:

$$
w_{0}=\delta(1-p)\left(W_{0}-W_{1}\right)
$$

The value function in state 0 is:

$$
W_{0}=\int_{w_{0}}^{\bar{v}}\left[v+\delta\left(p W_{0}+(1-p) W_{1}\right)\right] f(v) d v+F\left(w_{0}\right) \delta W_{0} .
$$

Equations (4)-(8) define the solution to the optimal decision of the firm who can work on at most two projects at a time. In a model without commitment $(p=1)$, the selection thresholds would be $w_{1}=w_{0}=0$. Now suppose $p<1$.

Proposition 2 For a decision maker who can work on at most two projects, the selection threshold is higher when one project is underway than when it is not committed, $w_{1}>w_{0}>0$.

If the firm has not yet selected any project, taking on the current project will tie resources but still leave an opportunity to select another promising project in the next period. However, for a firm that is already committed to one project, taking on a second project means that it cannot take on an additional project until the commitment to one of the projects ends, making the firm more selective $5^{5}$

Comparing firms with different capacity constraints, we find that the single project decision maker has a higher threshold of selection compared to the threshold of selection of the

\footnotetext{
${ }^{5}$ Interestingly, the inequality $w_{1}>w_{0}$ remains true in the limit where firms are infinitely patient $(\delta \rightarrow 1)$, when the firm is assumed to maximize the expected payoff per unit of time. The firm prefers to spend more time in states 0 and 1 than in state 2 (where it is committed and cannot accept projects). Setting $w_{1}>w_{0}$ is a way to steer the system back towards state 0 , as it gets closer to state 2 .
} 
two-project capacity firm, even when the two-project capacity firm has already committed resources to one project. Intuitively, for the two-project capacity firm, when all its resources are committed, the expected time until at least one of the commitments is relieved is shorter than for the single project capacity firm who has committed all of its resources. This is because the probability that one of the two projects ends is larger than the probability that one project ends.

Proposition 3 A firm that has a capacity of one project has a higher selection threshold than a two-project capacity firm, even when the two-project capacity firm has already committed resources to one project, i.e., $v_{0}>w_{1}$.

An implication of Proposition 3 is that the average return of selected projects is larger for a firm that has a more stringent project capacity constraint. The constrained firm does not select some of the low return projects that the less constrained firm would select.

\section{Strategic Project Selection}

In this section, we examine the project selection decisions in a duopoly setting. One firm's decision affects the payoffs of the other. We assume that a project can be selected by only one firm. We examine project selection strategies and the effects of competition on project selection.

\subsection{The Game}

We consider competition between two firms $A$ and $B$. Every period, a new project opportunity with a value $v$ drawn from the distribution $F(v)$ arises. If one firm is committed to an earlier project and the other is free, the free firm can decide whether to select the project. If both firms are free, one is chosen at random (with a probability $\frac{1}{2}$ ) to be that period's leader - the first firm to make a decision to select the project or not. If the period's leader selects the project, the follower cannot take on a project in that period. If the period's leader rejects the project, the follower can decide whether to select it. As we assumed in Section 
3.1, a firm can work on at most one project at a time and the commitment of resources ends each period with a probability $p$.

For a project with return $v$ to the selecting firm, the return for the other firm is $\gamma v$, where $\gamma \in(-1,1)$. If a firm's project selection has no effect on the market profits of the other firm, $\gamma=0$. This might be the case when a project is a service to a client. A firm can suffer a negative externality when the other firm selects, $\gamma<0$, for example if the project is a new technology that gives the selecting firm a cost advantage in some product market $]^{6}$ A firm can enjoy a positive externality when the other firm selects the project, $\gamma>0$, for example when there are technology spillovers. Payoffs $v$ and $\gamma v$ can also represent Stackelberg payoffs with the selecting firm being the market leader. We assume that the externality is smaller in magnitude than the return for the selecting firm, $|\gamma|<1$. If no firm selects the project, payoffs are zero for each firm.

We restrict attention to Markov strategies. A firm's decision will only depend on the current state. States of the world are denoted by $(i, j)$, where $i, j \in\{0,1\}$. In a state with $i=0$, firm $A$ is not committed and in a state with $i=1$, firm $A$ is committed. Similarly, $j$ indicates the commitment of firm $B$.

We look for a symmetric Markov perfect equilibrium. The value function (before realization of the project's return and the choice of the first mover) in any state $(i, j)$ is denoted by $V_{i, j}^{A}$ for firm $A$ and $V_{i, j}^{B}$ for firm $B$. Since in this section we focus on symmetric equilibria, $V_{i, j}^{A}=V_{j, i}^{B}=V_{i, j}$. Equilibrium strategies are characterized by threshold levels of return. The threshold for the non-committed firm in a state $(0,1)$ is denoted by $v_{0,1}$. In state $(0,0)$, the threshold for the period's leader (the first mover) is $v_{0,0}^{1}$ and the threshold is $v_{0,0}^{2}$ for the period's follower (who would consider selecting the project if the leader rejected it). We say that a threshold is interior if it is in the range $(\underline{v}, \bar{v})$, so that in every state in which at least one firm is free, the lowest value project is rejected, but the highest value project is accepted.

\footnotetext{
${ }^{6}$ Thomas (2013) analyzes a model of strategic experimentation with a negative externality. In her model, two players can choose between a risky and a safe option. Each player has exclusive access to a risky option. But they share the safe option that can only be used by one player at a time. Our results are not directly comparable as the models differ significantly.
} 


\subsection{Analysis}

We derive the conditions that define the equilibrium thresholds of selection and the values. In state $(1,1)$, both firms are committed and no firm can select a project. Next period's state depends on whether each of the firms is freed from its previous commitment. The value in state $(1,1)$ is thus given by:

$$
V_{1,1}=\delta\left[p^{2} V_{0,0}+p(1-p) V_{1,0}+p(1-p) V_{0,1}+(1-p)^{2} V_{1,1}\right]
$$

In state $(0,1)$, one firm is free, and can choose to select the project or to reject it so as to maximize:

$$
\max \{\underbrace{v+V_{1,1}}_{\text {select }}, \underbrace{\delta\left(p V_{0,0}+(1-p) V_{0,1}\right)}_{\text {reject }}\} .
$$

An interior threshold return for selection satisfies:

$$
v_{0,1}=\delta\left(p V_{0,0}+(1-p) V_{0,1}\right)-V_{1,1}
$$

Using the threshold $v_{0,1}$, the value functions in states $(0,1)$ and $(1,0)$ are:

$$
\begin{aligned}
V_{0,1} & =\int_{v_{0,1}}^{\bar{v}}\left(v+V_{1,1}\right) f(v) d v+F\left(v_{0,1}\right) \delta\left(p V_{0,0}+(1-p) V_{0,1}\right), \\
V_{1,0} & =\int_{v_{0,1}}^{\bar{v}}\left(\gamma v+V_{1,1}\right) f(v) d v+F\left(v_{0,1}\right) \delta\left(p V_{0,0}+(1-p) V_{1,0}\right) .
\end{aligned}
$$

In state $(0,0)$, one of the firms is chosen at random to be the leader who can consider the project first. If this firm does not select the project, then the follower faces the choice:

$$
\max \{\underbrace{v+\delta\left(p V_{0,0}+(1-p) V_{1,0}\right)}_{\text {select }}, \underbrace{\delta V_{0,0}}_{\text {reject }}\} .
$$

If the threshold is interior, it satisfies:

$$
v_{0,0}^{2}=\delta(1-p)\left(V_{0,0}-V_{1,0}\right)
$$

Returning to the leader's decision, if $v \geq v_{0,0}^{2}$, so that the second firm will select if it has the opportunity to do so, then the first firm faces the choice:

$$
\max \{\underbrace{v+\delta\left(p V_{0,0}+(1-p) V_{1,0}\right)}_{\text {select }}, \underbrace{\gamma v+\delta\left(p V_{0,0}+(1-p) V_{0,1}\right)}_{\text {reject } \Rightarrow \text { rival selects }}\} .
$$


The firm would select this project if $v \geq \widetilde{v}$ where:

$$
\widetilde{v}=\frac{\delta(1-p)}{(1-\gamma)}\left(V_{0,1}-V_{1,0}\right)
$$

If $v<v_{0,0}^{2}$, so that the follower will not select the project even if the leader rejects it, then the leader faces essentially the same choice as that of the follower after the leader rejected a project. Thus, for $v<v_{0,0}^{2}$, neither firm selects. Combining the results, the leader selects if $v \geq v_{0,0}^{1}$ where:

$$
v_{0,0}^{1}=\max \left\{v_{0,0}^{2}, \widetilde{v}\right\} \geq v_{0,0}^{2} .
$$

If $\widetilde{v}>v_{0,0}^{2}$, then there is a range of project returns $v_{0,0}^{2} \leq v<v_{0,0}^{1}$ so that the leader rejects, but the follower selects. The equation that defines the value function in state $(0,0)$ is given by:

$$
V_{0,0}=\frac{1+\gamma}{2} \int_{v_{0,0}^{2}}^{\bar{v}} v f(v) d v+\delta F\left(v_{0,0}^{2}\right) V_{0,0}+\delta\left[1-F\left(v_{0,0}^{2}\right)\right]\left[p V_{0,0}+(1-p) \frac{V_{0,1}+V_{1,0}}{2}\right]
$$

Lemma 1 For the game described in this section, a pure strategy equilibrium exists.

Existence of a pure strategy equilibrium follows from Brouwer's fixed point theorem. Uniqueness is not always guaranteed, but the equilibrium is unique at least for certain parameter values including small enough values of $p$ (long duration projects). It can be verified that given our assumptions on the parameters of the model, in any equilibrium all the thresholds must be interior. That is, when a firm is free to select, it does not reject all projects nor does it accept all projects.

\subsection{Strategic Rejection of Projects}

In the special case where $p=1$, each project lasts only one period. The commitment of resources is not a binding constraint. It follows immediately from the system above that the equilibrium thresholds are $v_{0,0}^{2}=v_{0,1}=v_{0,0}^{1}=0$. In this case, a firm will select any project that has a positive expected return, and the follower will never select a project that the leader rejected. We assume from now that $p<1$, so that commitment is necessary. 
In the presence of a rival, a firm's equilibrium strategy depends on whether its rival has previously committed resources. We show that a firm strategically rejects some projects that it would have selected had its rival been committed $\left(v_{0,0}^{1} \geq v_{0,1}\right)$.

When both firms are free of commitment, the leader in that period selects high value projects, and rejects low value projects. Interestingly, there is a range of intermediate value projects, $v \in\left(v_{0,0}^{2}, v_{0,0}^{1}\right)$, that the leader rejects, yet the follower, who is offered the same project, selects. This is true despite the fact that firms are identical: they have the same value from each project, have the same capacity constraint, and are chosen to be a period's leader with equal probability. The period's leader rejects an intermediate value project knowing that his rival will take it. When the rival commits to a project, the leader is in a better position in the next period (when he might no longer be the leader). For the follower, selecting an intermediate value project is better than rejecting it, since the leader already rejected it.

Proposition 4 In a symmetric Markov perfect equilibrium, the thresholds for selection in state $(0,0)$ satisfy $v_{0,0}^{1}>v_{0,0}^{2}$, so that in the range $v_{0,0}^{1}>v \geq v_{0,0}^{2}$, the first firm rejects the project, but the second firm selects it. Additionally, $v_{0,0}^{1} \geq v_{0,1}$, (with a strict inequality for $p<1)$, so that a firm is more selective when its rival is not committed.

By (15), we know that $v_{0,0}^{1} \geq v_{0,0}^{2}$. This means that a leader never takes on a project that would have been rejected by the follower. In the proof of Proposition 4, we show that the inequality is strict whenever projects require commitment $(p<1)$.

We have assumed that the magnitude of the externality is smaller than the direct effect of selection, $|\gamma|<1$. The result in Proposition 4 does not hold when $|\gamma|=1$. If $\gamma=(-1)$, then the gain of one firm is the loss of another. In this case, $V_{0,0}=V_{1,1}=0, V_{0,1}=-V_{1,0}$, and all the thresholds are equal: $v_{0,0}^{1}=v_{0,0}^{2}=v_{0,1}$. If $\gamma=1$, (11) and (12) imply that $V_{0,1}=V_{1,0}$. In state $(0,0)$, whenever the follower would accept a project $\left(v>v_{0,0}^{2}\right)$, the leader is indifferent between accepting and rejecting. So in one solution to the system, $v_{0,0}^{1}=v_{0,0}^{2}$.

While the general patterns of project selection we described above hold for any value of the externality parameter $\gamma \in(-1,1)$, clearly the equilibrium thresholds depend on the $\gamma$. 
For long duration projects, we show that the thresholds decrease with $\gamma \sqrt{7}$ In the presence of positive externalities, the thresholds of selection are lower (more projects are taken on by the firm) than in the presence of negative externalities. Intuitively, a firm is less worried about committing its resources, because it expects to benefit also from future projects that its opponent selects.

Proposition 5 For projects of long duration (p close to 0 ), the selection thresholds $\left(v_{0,0}^{1}, v_{0,0}^{2}, v_{0,1}\right)$ are (weakly) decreasing with $\gamma$.

We next compare the equilibrium selection behavior to two benchmarks. First, in Section 4.4, we compare the behavior of a firm with a one project capacity constraint to that of an equally constrained monopolist (a single project decision maker). Then, in Section 4.5, we compare the outcome of the non-cooperative game to that of two firms that collaborate to achieve the highest total payoff.

\subsection{Competition and the Project Selection}

A vast literature in economics debates the relation between market structure and innovation (see Gilbert, 2006, for a survey). Our model offers a new look at this question in comparing project selection in a monopoly market structure to that in a duopoly market when projects require commitment of resources, and firms are constrained to work on at most one project at a time.

To examine the effects of competition on project selection, we compare the selection strategies in the duopoly game we analyzed earlier in this section to the selection behavior of the single decision maker we studied in Section 3.1. We show that the threshold of return for a project to be selected is lower when two firms compete than when there is a single decision maker who is constraint to adopt one project. Thus, in a duopoly market, more projects are selected than in a monopoly market (even though we assumed project opportunities arise at the same rate regardless of market structure). However, since the threshold of selection is

\footnotetext{
${ }^{7}$ The condition that $p$ is small is sufficient but not necessary. The derivatives were too complex to sign for general values of $p$.
} 
higher for the monopolist, the monopolist will tend to work on projects that have a higher expected return.

Proposition 6 Selection thresholds are lower in duopoly competition than for a monopolist: $v_{0,0}^{1}<v_{0}$.

The comparison in Proposition 6 is done under the assumption that the project return is drawn from the same distribution in the single decision maker's problem and in the game. If the firm enjoys a higher return from any project when it is alone in the market, the distribution of returns in the decision maker's problem may dominate that in the duopoly case. As we have shown in Proposition 1, this would imply an even higher threshold of selection. So the result of Proposition 6 holds even if the monopolist earns more from each project compared to the duopolist.

The comparison made in this section assumes that the monopolist is also a firm that is constrained to work on at most one project at a time. We analyze the comparison between the duopoly and a monopolist who has a two-project capacity in the next section.

\subsection{Joint Decision versus the Non-cooperative Game}

The two-project capacity version we analyzed in Section 3.2 allows us to compare project selection decisions of strategic non-cooperative firms with the decision of a joint venture. We adjust the system of equations (4)-(8) which was derived for the two-project capacity firm so that the return from a selected project is $v(1+\gamma)$, which is the sum of payoffs in the game we solved in the previous section (the revised system is stated in the proof of Proposition 7). It is easy to verify that the thresholds $w_{i}$ that solve the system (4)-(8) also solve this new system. We are interested in two comparisons. First, we compare the selection threshold of the joint venture that is committed to one project, but can still select another $\left(w_{1}\right)$, to the selection threshold of the non-cooperative firm that is not committed and has a rival who is committed $\left(v_{0,1}\right)$. In both these cases, one firm is committed and one is free. Second, we compare the threshold of the joint venture when it is free of commitments $\left(w_{0}\right)$, to the selection threshold above which at least one of the non-cooperatively competing firms in 
the game selects the project when both firms are free of commitment $\left(v_{0,0}^{2}\right)$. In both these situations, the two firms are free.

Proposition 7 A non-cooperatively competing duopolist has higher selection thresholds compared to the jointly optimal decision maker, $w_{1}<v_{0,1}$ and $w_{0}<v_{0,0}^{2}$.

To prove this proposition, we first argue that the joint decision maker can obtain at least as high a value in state 0 as the sum of values of both firms in the game in state $(0,0)$, i.e., $W_{0} \geq 2 V_{0,0}$. This is true because the decision maker can mimic the equilibrium selection strategies in the game. We then derive the given inequalities on thresholds from the systems of dynamic programming equations. Proposition 7 suggests that competition between firms with capacity constraints on project selections results in these firms setting too high a bar for selection, compared to what would be optimal for them under joint decision making. In our model, $|\gamma|<1$.If however $\gamma=1$, so that a player obtains the same payoff whether he or his rival selects a project, then the payoffs in equilibrium are equal to the payoffs of the joint venture, and the inequalities in Proposition 7 are replaced with equalities.

\section{A Dominant Firm}

Our analysis in Section 4 assumed that the two firms are symmetric, in particular, that the order by which they are presented with a project is random. Our finding that a follower selects a project that was rejected by the leader is perhaps the most striking in a symmetric setting. Asymmetry could be another reason why firms sometimes reject projects that their rivals then select. Clearly, if the leader values a project less than the follower, the follower might select a project that the leader rejected. But even if two firms agree on the value of a project, there can be asymmetry in the determination of priority (who gets to choose first). It is possible that one firm has an advantage and is more often the first to consider a project. For example, one firm may be better known, or easier to approach, or project ideas may start within this firm.

In Cassiman and Ueda (2006), innovations arise within the established firm. If the firm chooses not to commercialize them internally, a new startup firm commercializes the innovation externally. In this section, we assume that, as in Cassiman and Ueda (2006), one of 
the firms is always the first to consider a new project. Our results still differ. Cassiman and Ueda predict that the established firm (who is always the leader) will choose to commercialize internal innovations with lower profitability compared to the innovations they leave for external developers. They note however that this prediction is not in line with the empirical findings of Gompes and Lerner (2000). In contrast, we also find in the dominant firm game that the leader (this time always the dominant firm) will select the highest value projects, and the follower will sometimes select intermediate value projects that were rejected by the leader.

In the dominant firm model, there is a new motive for the follower to select rejected projects. The follower faces an inferior (right-censored) distribution of projects, and therefore is less selective than the dominant firm. As a result, the follower will want to select some projects that the dominant firm rejects. When there are no payoff externalities $(\gamma=0)$, the dominant firm would have no reason to keep its rival busy, as it is always the one who gets to choose first. So the only reason for the intermediate range to arise is the inferior distribution that the follower faces. For other values of $\gamma$, or if the dominant firm has a higher probability of being the leader (but still less than 1) both forces could be present.

Let us assume now that firm $A$ is a dominant firm; when its resources are not committed, firm $A$ is always the first to consider a project. If it rejects the project, firm $B$, the follower, can decide whether or not to select it.

In state $(1,1)$, no firm can select a project. The value in state $(1,1)$ is thus given by:

$$
V_{1,1}^{i}=\delta\left[p^{2} V_{0,0}^{i}+p(1-p) V_{1,0}^{i}+p(1-p) V_{0,1}^{i}+(1-p)^{2} V_{1,1}^{i}\right] \text { for } i=A, B
$$

In states $(0,1)$, and $(1,0)$, the firm who is not committed can either select the project and immediately transition to the state $(1,1)$ where both firms are committed, or reject and transition in the next period to one of the states where it is not committed. Hence, the thresholds for selecting projects are given by:

$$
\begin{aligned}
& v_{0,1}^{A}=\delta\left(p V_{0,0}^{A}+(1-p) V_{0,1}^{A}\right)-V_{1,1}^{A} \\
& v_{1,0}^{B}=\delta\left(p V_{0,0}^{B}+(1-p) V_{1,0}^{B}\right)-V_{1,1}^{B} .
\end{aligned}
$$

Accounting for these thresholds of selection for the non-committed firm, the value func- 
tions in states $(0,1)$ and $(1,0)$ are:

$$
\begin{aligned}
V_{0,1}^{A} & =\int_{v_{0,1}^{A}}^{\bar{v}}\left(v+V_{1,1}^{A}\right) f(v) d v+F\left(v_{0,1}^{A}\right) \delta\left(p V_{0,0}^{A}+(1-p) V_{0,1}^{A}\right), \\
V_{0,1}^{B}= & \int_{v_{0,1}^{A}}^{\bar{v}}\left(\gamma v+V_{1,1}^{B}\right) f(v) d v+F\left(v_{0,1}^{A}\right) \delta\left(p V_{0,0}^{B}+(1-p) V_{0,1}^{B}\right),
\end{aligned}
$$

and

$$
\begin{aligned}
V_{1,0}^{A} & =\int_{v_{1,0}^{B}}^{\bar{v}}\left(\gamma v+V_{1,1}^{A}\right) f(v) d v+F\left(v_{1,0}^{B}\right) \delta\left(p V_{0,0}^{A}+(1-p) V_{1,0}^{A}\right), \\
V_{1,0}^{B} & =\int_{v_{1,0}^{B}}^{\bar{v}}\left(v+V_{1,1}^{B}\right) f(v) d v+F\left(v_{1,0}^{B}\right) \delta\left(p V_{0,0}^{B}+(1-p) V_{1,0}^{B}\right) .
\end{aligned}
$$

In state $(0,0)$, firm $A$ decides first whether to select the period's project. If firm $A$ rejects the project, then firm $B$ 's selection threshold level is:

$$
v_{0,0}^{B}=\delta(1-p)\left(V_{0,0}^{B}-V_{0,1}^{B}\right)
$$

Returning to $A$ 's decision, if $v \geq v_{0,0}^{B}$, so that $B$ will select if it has the opportunity to do so, then the leader firm $A$ would select this project if the following condition holds:

$$
v \geq \frac{\delta(1-p)}{(1-\gamma)}\left(V_{0,1}^{A}-V_{1,0}^{A}\right):=\widetilde{v} .
$$

While in the symmetric case the leader never selects a project that would be rejected by the follower, with asymmetry this is not necessarily so. If $v<v_{0,0}^{B}$, so that the second firm will not select the project even if firm $A$ did not, then $A$ faces the choice:

$$
\max \{\underbrace{v+\delta\left(p V_{0,0}^{A}+(1-p) V_{1,0}^{A}\right)}_{\text {select }}, \underbrace{\delta V_{0,0}^{A}}_{\text {reject } \Rightarrow \text { no one selects }}\} .
$$

The threshold is:

$$
\widetilde{\widetilde{v}}=\delta(1-p)\left(V_{0,0}^{A}-V_{1,0}^{A}\right)
$$

From these derivations, Proposition 8 follows. 
Proposition 8 For $p<1$, in a Markov perfect equilibrium, in state $(0,0)$, projects of sufficiently high return are selected by the dominant firm $A$ and projects of sufficiently low return are rejected by both firms. There exist thresholds $\widetilde{v}$ and $v_{0,0}^{B}$ so that in state $(0,0)$ in the range $\widetilde{v}>v \geq v_{0,0}^{B}$, the dominant firm rejects the project, but the follower selects it. There is a range of parameter values for which this intermediate range is non-empty.

The system of equations defining the values is more complex in this asymmetric version of the model. But it becomes simple when $p=0$ (project commitments are permanent) and $\gamma=0$ (there are no externalities). For $p$ and $\gamma$ close to zero, it is easy to verify that the range in which firm $A$ rejects intermediate value projects but firm $B$ selects it, is non-empty $\left(\widetilde{v}>v_{0,0}^{B}\right)$. For these parameter values, it is also true that $\widetilde{v} \geq v_{0,0}^{B}$, so in state $(0,0)$ the dominant firm never selects a project that would have been rejected by firm $B$.

\section{Concluding Remarks}

Projects often require firms to commit limited resources, preventing them from selecting other projects while they are committed. Since more promising projects could arise during the time a firm is committed to a project it selected earlier, constrained firms reject some profitable projects.

The selection threshold of a single decision maker that can work on at most one project at a time is higher when project commitment is expected to last longer, or when the firm is more patient. The reservation value is also higher for firms that face a first order stochastically dominating distribution of project returns. A less constrained firm, that has a two-project capacity, has lower selection thresholds than a one-project capacity firm, even during a period when it is already committed to one project and has resources available only for one other project.

In a strategic environment, project selection by one firm can change the profitability of a rival, as well as the rival's opportunity to take on projects. In the symmetric game, we show that a firm sometimes rejects a project that will then be selected by a rival, as this can lessen future competition on projects. In an asymmetric game, the follower is less selective also because it faces an inferior distribution of projects. 
Our paper provides new insights into the relation between market structure and innovations. We show that a duopolist has lower selection thresholds than an identical firm who operates as a monopoly. Thus competition induces more projects to be selected, but the average quality of projects selected by the monopolist is higher. If however the two firms are able to jointly make selection decisions, then the selection thresholds of the single less constrained decision maker are lower than in the non-cooperative equilibrium.

In attempting to maintain tractability and a simple exposition, we made certain simplifying assumptions. In our model, if the firm is committed to a project, it cannot select another project until the commitment ends. In reality, it is likely that firms can at some cost be released from a previous commitment. We analyzed the case in which the cost of abandoning a project is high enough so that the commitment is always binding. More generally, when the cost is not too high, if a new project of high enough return arises, the firm might find it worthwhile to abandon an old project and select the new. We expect the results to be qualitatively similar, with perhaps lower selection thresholds because the commitment is less binding. A formal analysis is left for future work. 8

In analyzing strategic interactions, our model assumes sequential decisions. We argue that in many economic environments this assumption is reasonable, e.g., clients likely approach service providers sequentially. However, there may be some markets in which firms simultaneously decide on project selection, or the order of sequential move might be endogenous as well. If, in each period, firms simultaneously decide on selection, and each gets the project with equal probability when they both attempt to select, there is a range of intermediate value project returns for which firms randomize the decision to select. This result is analogous to our findings here in that there is a positive probability that one firm would reject a project that its symmetric rival selects.

Our analysis is focused on the strategic behavior of the firms that select projects. If, however, project opportunities arise when independent innovators propose them, they might

\footnotetext{
${ }^{8}$ When there is a cost to abandon the project, and project returns are only obtained conditional on the project being completed, the problem becomes much more complex because in addition to the thresholds of a free firm, in a committed state, the firm's threshold for abandoning the current project for a new project depends on the expected return of a current project.
} 
also act strategically so as to extract surplus from the selecting firms. The game played in each period might take the form of an auction or a bargaining game. These extensions are interesting directions for future work.

\section{A Appendix: Proofs}

Proof of Proposition 1. (i) Re-arranging (1) and (3), then substituting into (2), we obtain the following implicit definition of the selection decision threshold $v_{0}$ :

$$
\frac{1-\delta(1-p)}{\delta(1-p)} v_{0}=\int_{v_{0}}^{\bar{v}}\left(v-v_{0}\right) f(v) d v
$$

From (25), we know that $v_{0}$ is the solution to $g(x)=0$ where $g($.$) takes the following form:$

$$
g(x)=\frac{[1-\delta(1-p)]}{\delta(1-p)} x-\int_{x}^{\bar{v}}(v-x) f(v) d v .
$$

Evaluating $g(x)$ at $x=0$ and at $x=\bar{v}$, we find that $g(0)<0$ and $g(\bar{v})>0$. Additionally,

$$
g^{\prime}(x)=\frac{[1-\delta(1-p)]}{\delta(1-p)}+[1-F(x)]>0
$$

This implies that for given $\delta$ and $p$, there exists a unique solution to 26 in the range $(0, \bar{v})$.

(ii) Consider $g\left(v_{0} ; \delta, p\right)$ referring to $g$ as defined in $(26)$ evaluated at $v_{0}$ and accounting $\delta, p$ as arguments of the function. Implicit differentiation of $g\left(v_{0} ; \delta, p\right)=0$ shows that:

$$
\begin{gathered}
\frac{\partial g}{\partial v_{0}} \frac{d v_{0}}{d p}+\frac{\partial g}{\partial p}=0 \Rightarrow \frac{d v_{0}}{d p}=-\frac{\partial g}{\partial p} / \frac{\partial g}{\partial v_{0}} \\
\frac{\partial g}{\partial v_{0}} \frac{d v_{0}}{d \delta}+\frac{\partial g}{\partial \delta}=0 \Rightarrow \frac{d v_{0}}{d \delta}=-\frac{\partial g}{\partial \delta} / \frac{\partial g}{\partial v_{0}}
\end{gathered}
$$

From the proof of (i), we know that $\frac{\partial g}{\partial v_{0}}>0$. Hence,

$$
\operatorname{sign}\left(\frac{d v_{0}}{d p}\right)=\operatorname{sign}\left(-\frac{\partial g}{\partial p}\right)=\operatorname{sign}\left[-\frac{v_{0}}{\delta(1-p)^{2}}\right]<0 .
$$

Similarly,

$$
\operatorname{sign}\left(\frac{d v_{0}}{d \delta}\right)=\operatorname{sign}\left(-\frac{\partial g}{\partial \delta}\right)=\operatorname{sign}\left[\frac{v_{0}}{\delta^{2}(1-p)}\right]>0 .
$$

(iii) Consider two cumulative distribution functions $F^{a}$ and $F^{b}$, defined on the interval $[\underline{v}, \bar{v}]$ so that $F^{b}$ first order stochastically dominates $F^{a}$, i.e., $F^{b}(v) \leq F^{a}(v)$. For each 
distribution, the threshold of return $v_{0}^{a}$ and $v_{0}^{b}$ solves $g^{i}(v)=0$ where $g^{i}$ is as defined in 26) with the distribution $F^{i}, i=a, b$. Using integration by parts, we rearrange the function $g^{i}$ and write it as:

$$
g^{i}\left(v_{0}\right)=\frac{[1-\delta(1-p)]}{\delta(1-p)} v_{0}-\int_{v_{0}}^{\bar{v}}\left[1-F_{i}(v)\right] d v, i=a, b .
$$

Therefore $g^{b}(v) \leq g^{a}(v)$. In particular, $g^{b}\left(v_{0}^{a}\right) \leq g^{a}\left(v_{0}^{a}\right)=0$. Since the function $g^{b}$ is increasing, this implies that $v_{0}^{a} \leq v_{0}^{b}$, which is the desired conclusion.

Consider two cumulative distribution functions $F^{b}$ and $F^{a}$ defined on $\left[\underline{v}^{b}, \bar{v}^{b}\right]$ and $\left[\underline{v}^{a}, \bar{v}^{a}\right] \subset$ $\left[\underline{v}^{b}, \bar{v}^{b}\right]$ respectively so that $F^{b}$ is a mean preserving spread of $F^{a}$, (or $F^{a}$ second order stochastically dominates $\left.(\operatorname{SOSD}) F^{a}\right)$. Define $F^{a}(v)=0$ for all $v<\underline{v}^{a}$, and $F^{a}(v)=1$ for all $v>\bar{v}^{a}$. Then,

$$
g^{b}\left(v_{0}^{a}\right)=g^{b}\left(v_{0}^{a}\right)-g^{a}\left(v_{0}^{a}\right)=\int_{v_{0}^{a}}^{\bar{v}^{b}}\left[F^{b}(v)-F^{a}(v)\right] d v \underset{\text { by SOSD }}{\leq} 0 .
$$

Because the function $g^{b}$ is increasing, $g^{b}\left(v_{0}^{a}\right) \leq 0$ implies that $v_{0}^{a} \leq v_{0}^{b}$, which is the desired conclusion.

Proof of Proposition 2. Using (5), we can re-write (6) as follows:

$$
W_{1}=\int_{w_{1}}^{\bar{v}}\left(v-w_{1}\right) f(v) d v+\delta\left(p W_{0}+(1-p) W_{1}\right) .
$$

Similarly, using (7), we can re-write (8) as follows:

$$
W_{0}=\int_{w_{0}}^{\bar{v}}\left(v-w_{0}\right) f(v) d v+\delta W_{0}
$$

Substituting the two equations above into (7) and re-arranging, we get:

$$
\frac{[1-\delta(1-p)]}{\delta(1-p)} w_{0}=\int_{w_{0}}^{\bar{v}}\left(v-w_{0}\right) f(v) d v-\int_{w_{1}}^{\bar{v}}\left(v-w_{1}\right) f(v) d v
$$


Again, substituting (4), (7) and (28) into (5), we get:

$$
\begin{aligned}
w_{1} & =\delta\left(p W_{0}+(1-p) W_{1}\right)-\frac{\delta}{\left[1-\delta(1-p)^{2}\right]}\left[p^{2} W_{0}+2 p(1-p) W_{1}\right] \\
& =\frac{\delta(1-p)^{2}}{\left[1-\delta(1-p)^{2}\right]}(1-\delta) W_{0}-\left[1-\frac{2 p}{\left[1-\delta(1-p)^{2}\right]}\right] w_{0} \\
& =\frac{\delta(1-p)^{2}}{\left[1-\delta(1-p)^{2}\right]} \int_{w_{0}}^{\bar{v}}\left(v-w_{0}\right) f(v) d v-\left[1-\frac{2 p}{\left[1-\delta(1-p)^{2}\right]}\right] w_{0} .
\end{aligned}
$$

Substituting (30) into this expression and re-arranging, we get:

$$
\frac{[1-\delta(1-p)]}{\delta(1-p)} w_{1}=\int_{w_{1}}^{\bar{v}}\left(v-w_{1}\right) f(v) d v+\frac{p}{\delta(1-p)^{2}}\left(w_{0}-w_{1}\right)
$$

We re-write (30) and (31) substituting the function $g($.$) that was defined in (26)$ :

$$
\begin{aligned}
g\left(w_{0}\right) & =-\int_{w_{1}}^{\bar{v}}\left(v-w_{1}\right) f(v) d v \\
g\left(w_{1}\right) & =\frac{p}{\delta(1-p)^{2}}\left(w_{0}-w_{1}\right) .
\end{aligned}
$$

For all $p<1$, if $w_{0} \geq w_{1}$, then $g\left(w_{1}\right) \geq 0>g\left(w_{0}\right)$ which implies $w_{1}>w_{0}$ (because $g($.$) is$ increasing), a contradiction! Hence, $w_{1}>w_{0}$ for all $p<1$. Finally, $w_{0}>0$ follows from (30) and $w_{1}>w_{0}$.

Proof of Proposition 3. Note that we assume project values are drawn from the same distribution in either the two projects or the single project capacity model. From the proof of Proposition 1(i), we know that $v_{0}$ is the solution to a strictly increasing function $g\left(v_{0}\right)=0$. From the proof of Proposition 2, we know that $w_{1}>w_{0}$ for all $p<1$ and by (33) we know that $g\left(w_{1}\right)<0$. It follows that:

$$
g\left(v_{0}\right)=0>g\left(w_{1}\right)>g\left(w_{0}\right) .
$$

This implies that $v_{0}>w_{1}>w_{0}$ because $g($.$) is increasing.$

Proof of Lemma 1. An equilibrium is defined by the system (9)-(16). Accounting for 
corner solutions, we re-write the thresholds as:

$$
\begin{aligned}
v_{0,1} & =\operatorname{median}\left\{\underline{v}, \delta\left(p V_{0,0}+(1-p) V_{0,1}\right)-V_{1,1}, \bar{v}\right\} \\
v_{0,0}^{2} & =\operatorname{median}\left\{\underline{v}, \delta(1-p)\left(V_{0,0}-V_{1,0}\right), \bar{v}\right\} \\
\widetilde{v} & =\operatorname{median}\left\{\underline{v}, \frac{\delta(1-p)}{(1-\gamma)}\left(V_{0,1}-V_{1,0}\right), \bar{v}\right\} \\
v_{0,0}^{1} & =\max \left\{v_{0,0}^{2}, \widetilde{v}\right\} .
\end{aligned}
$$

These thresholds are in the range $[\underline{v}, \bar{v}]$, and written as a function of the four values $\left\{V_{1,1}, V_{0,1}, V_{1,0}, V_{0,0}\right\}$. Thus the system of equations that defines the equilibrium can be reduced to a system of 4 equations in these 4 unknowns. We substitute (9) into (11) and $(12)$ to obtain this system in values $\left\{V_{1,1}, V_{0,1}, V_{1,0}, V_{0,0}\right\}$ :

$$
\begin{aligned}
V_{1,1}= & \delta\left[p^{2} V_{0,0}+p(1-p) V_{1,0}+p(1-p) V_{0,1}+(1-p)^{2} V_{1,1}\right], \\
V_{0,1}= & {\left[\begin{array}{c}
\int_{v_{0,1}}^{\bar{v}}\left(v+\delta\left[p^{2} V_{0,0}+p(1-p) V_{1,0}+p(1-p) V_{0,1}+(1-p)^{2} V_{1,1}\right]\right) f(v) d v \\
+F\left(v_{0,1}\right) \delta\left(p V_{0,0}+(1-p) V_{0,1}\right)
\end{array}\right], } \\
V_{1,0}= & {\left[\begin{array}{c}
\int_{v_{0,1}}^{\bar{v}}\left(\gamma v+\delta\left[p^{2} V_{0,0}+p(1-p) V_{1,0}+p(1-p) V_{0,1}+(1-p)^{2} V_{1,1}\right]\right) f(v) d v \\
+F\left(v_{0,1}\right) \delta\left(p V_{0,0}+(1-p) V_{1,0}\right)
\end{array}\right], } \\
V_{0,0}= & \int_{v_{0,0}^{2}}^{\frac{(1+\gamma)}{2} v f(v) d v+\delta F\left(v_{0,0}^{2}\right) V_{0,0}+\delta\left[1-F\left(v_{0,0}^{2}\right)\right] \frac{(1-p)\left(V_{0,1}+V_{1,0}\right)+2 p V_{0,0}}{2},}
\end{aligned}
$$

where the thresholds are given above. The right hand side is a continuous function from the compact set $\left[\frac{1}{1-\delta} \underline{v}, \frac{1}{1-\delta} \bar{v}\right]^{4}$ to the same set. By Brouwer's theorem, a fixed point for this system exists. The fixed point satisfies the system (9)-(16) and it is therefore an equilibrium.

Proof of Proposition 4. By (15), $v_{0,0}^{1}=\max \left\{v_{0,0}^{2}, \widetilde{v}\right\} \geq v_{0,0}^{2}$, and $v_{0,0}^{1}>v_{0,0}^{2}$ iff $\widetilde{v}>v_{0,0}^{2}$. We need to show that $\widetilde{v}>v_{0,0}^{2}$. We first reduce the system $(9)-(16)$ that defines the equilibrium to a system of three equations in the three unknowns: $\widetilde{v}, v_{0,1}$ and $v_{0,0}^{2}$, using substitution and simple manipulations. Details of the derivations of this system are available from the authors upon request. The reduced system is given by:

$$
\frac{[1-\delta(1-p)]}{\delta(1-p)} \widetilde{v}=\int_{v_{0,1}}^{\bar{v}}(v-\widetilde{v}) f(v) d v
$$




$$
\begin{gathered}
\frac{[1-\delta(1-p)]}{\delta(1-p)} v_{0,1}=\int_{v_{0,1}}^{\bar{v}}\left(v-v_{0,1}\right) f(v) d v+\frac{p\left(v_{0,0}^{2}-v_{0,1}\right)}{\delta(1-p)^{2}} \\
\frac{[1-\delta(1-p)]}{\delta(1-p)} v_{0,0}^{2}=\left(\begin{array}{c}
\int_{v_{0,0}^{2}}^{\bar{v}}\left(v-v_{0,0}^{2}\right) f(v) d v-\frac{(1-\gamma)}{2} \int_{v_{0,0}^{2}}^{\bar{v}}(v-\widetilde{v}) f(v) d v \\
-\int_{v_{0,1}}^{\bar{v}}\left(v-v_{0,1}\right) f(v) d v+(1-\gamma) \int_{v_{0,1}}^{\bar{v}}(v-\widetilde{v}) f(v) d v
\end{array}\right) .
\end{gathered}
$$

It is easy to verify that given $|\gamma|<1, v_{0,0}^{2}=v_{0,1}=\widetilde{v}$ will be a solution to the system iff $p=1$. Now suppose $p<1$.

By (34) and (35),

$$
v_{0,1} \geq \widetilde{v} \Leftrightarrow \frac{[1-\delta(1-p)]}{\delta(1-p)} v_{0,1}-\int_{v_{0,1}}^{\bar{v}}\left(v-v_{0,1}\right) f(v) d v \geq 0 \Leftrightarrow p\left(v_{0,0}^{2}-v_{0,1}\right) \geq 0 .
$$

Thus, for $p=0$, we have $v_{0,1}=\widetilde{v}$ and for $p>0$ we have either $v_{0,0}^{2} \geq v_{0,1} \geq \widetilde{v}$ or $\widetilde{v} \geq v_{0,1} \geq$ $v_{0,0}^{2}$.

By the definition of $g$ in $(26)$ and from $(35)$ and $(36)$, we have:

$$
\begin{aligned}
& g\left(v_{0,0}^{2}\right)-g\left(v_{0,1}\right) \\
& =\left(\begin{array}{c}
{\left[\frac{[1-\delta(1-p)]}{\delta(1-p)} v_{0,0}^{2}-\int_{v_{0,0}^{2}}^{\bar{v}}\left(v-v_{0,0}^{2}\right) f(v) d v\right]} \\
-\left[\frac{[1-\delta(1-p)]}{\delta(1-p)} v_{0,1}-\int_{v_{0,1}}^{\bar{v}}\left(v-v_{0,1}\right) f(v) d v\right]
\end{array}\right) \\
& =\left[-\frac{(1-\gamma)}{2} \int_{v_{0,0}^{2}}^{\bar{v}}(v-\widetilde{v}) f(v) d v-\int_{v_{0,1}}^{\bar{v}}\left(v-v_{0,1}\right) f(v) d v+(1-\gamma) \int_{v_{0,1}}^{\bar{v}}(v-\widetilde{v}) f(v) d v\right] \\
& -\left[\frac{[1-\delta(1-p)]}{\delta(1-p)} v_{0,1}-\int_{v_{0,1}}^{\bar{v}}\left(v-v_{0,1}\right) f(v) d v\right]
\end{aligned}
$$




$$
\begin{aligned}
& =\left(\begin{array}{c}
-\frac{(1-\gamma)}{2} \int_{v_{0,0}^{2}}^{\bar{v}}(v-\widetilde{v}) f(v) d v-\gamma \int_{v_{0,1}}^{\bar{v}}(v-\widetilde{v}) f(v) d v \\
+\int_{v_{0,1}}^{\bar{v}}(v-\widetilde{v}) f(v) d v-\frac{[1-\delta(1-p)]}{\delta(1-p)} v_{0,1}
\end{array}\right) \\
& =\left(\begin{array}{c}
-\frac{(1-\gamma)}{2} \int_{v_{0,0}^{2}}^{\bar{v}}(v-\widetilde{v}) f(v) d v-\gamma \int_{v_{0,1}}^{\bar{v}}(v-\widetilde{v}) f(v) d v \\
+\frac{[1-\delta(1-p)]}{\delta(1-p)} \widetilde{v}-\frac{[1-\delta(1-p)]}{\delta(1-p)} v_{0,1} \\
\bar{v}
\end{array}\right), \text { from }(34) \\
& =-\frac{(1-\gamma)}{2} \int_{v_{0,0}^{2}}^{\bar{v}}(v-\widetilde{v}) f(v) d v-\gamma \int_{v_{0,1}}(v-\widetilde{v}) f(v) d v-\frac{[1-\delta(1-p)]}{\delta(1-p)}\left(v_{0,1}-\widetilde{v}\right) .
\end{aligned}
$$

If $v_{0,0}^{2} \geq v_{0,1} \geq \widetilde{v}$, then

$$
\int_{v_{0,0}^{2}}^{\bar{v}}(v-\widetilde{v}) f(v) d v \leq \int_{v_{0,1}}^{\bar{v}}(v-\widetilde{v}) f(v) d v
$$

Also, we know $\gamma>-\frac{(1-\gamma)}{2}$ because $\gamma \in(-1,1)$, which implies,

$$
\left[\left(-\frac{(1-\gamma)}{2}\right) \int_{v_{0,0}^{2}}^{\bar{v}}(v-\widetilde{v}) f(v) d v-\gamma \int_{v_{0,1}}^{\bar{v}}(v-\widetilde{v}) f(v) d v\right]<0 .
$$

Hence, if $v_{0,0}^{2} \geq v_{0,1} \geq \widetilde{v}$, then $\left[g\left(v_{0,0}^{2}\right)-g\left(v_{0,1}\right)\right]<0$ which is a contradiction because $g$ is strictly increasing. Therefore, by (37), if $p=0$, it must be that $\widetilde{v}=v_{0,1}>v_{0,0}^{2}$, and if $p>0$, then it has to be the case that $\widetilde{v}>v_{0,1}>v_{0,0}^{2}$.

Proof of Proposition 5. Subtracting the right hand side from the left hand side of each equation (34), (35) and (36), we get the following:

$$
\begin{aligned}
h_{1}\left(\widetilde{v}, v_{0,1} ; \delta, p\right) & :=\frac{[1-\delta(1-p)]}{\delta(1-p)} \widetilde{v}-\int_{v_{0,1}}^{\bar{v}}(v-\widetilde{v}) f(v) d v \\
h_{2}\left(v_{0,1}, v_{0,0}^{2} ; \delta, p\right) & :=\frac{[1-\delta(1-p)]}{\delta(1-p)} v_{0,1}-\int_{v_{0,1}}^{\bar{v}}\left(v-v_{0,1}\right) f(v) d v+\frac{p\left(v_{0,1}-v_{0,0}^{2}\right)}{\delta(1-p)^{2}}, \\
h_{3}\left(\widetilde{v}, v_{0,1}, v_{0,0}^{2} ; \delta, p, \gamma\right) & :=\frac{\left[1-2 p-\delta(1-p)^{2}\right]}{\delta(1-p)^{2}} v_{0,0}^{2}-\left[\begin{array}{c}
\int_{v_{0,0}^{2}}^{\bar{v}}\left(v-v_{0,0}^{2}\right) f(v) d v-\frac{\left[1-\delta(1-p)^{2}\right]}{\delta(1-p)^{2}} v_{0,1} \\
\left.+\frac{(1-\gamma)}{2}\left(\frac{[1-\delta(1-p)]}{\delta(1-p)} \widetilde{v}+\int_{v_{0,0}^{2}}^{v_{0,1}}(\widetilde{v}-v) f(v) d v\right)\right] .
\end{array}\right.
\end{aligned}
$$


Implicitly differentiating the three equations above with respect to the parameter $\gamma$, we get:

$$
\begin{aligned}
& \frac{d \widetilde{v}}{d \gamma}= \frac{\left(\frac{\partial h_{3}}{\partial v_{0,1}} \frac{\partial h_{1}}{\partial \gamma}-\frac{\partial h_{1}}{\partial v_{0,1}} \frac{\partial h_{3}}{\partial \gamma}\right) \frac{\partial h_{2}}{\partial v_{0,0}^{2}}+\left(\frac{\partial h_{1}}{\partial v_{0,1}} \frac{\partial h_{2}}{\partial \gamma}-\frac{\partial h_{1}}{\partial \gamma} \frac{\partial h_{2}}{\partial v_{0,1}}\right) \frac{\partial h_{3}}{\partial v_{0,0}^{2}}}{\left[\frac{\partial h_{1}}{\partial \widetilde{v}} \frac{\partial h_{2}}{\partial v_{0,1}} \frac{\partial h_{3}}{\partial v_{0,0}^{2}}-\frac{\partial h_{1}}{\partial \widetilde{v}} \frac{\partial h_{2}}{\partial v_{0,0}^{2}} \frac{\partial h_{3}}{\partial v_{0,1}}+\frac{\partial h_{1}}{\partial v_{0,1}} \frac{\partial h_{2}}{\partial v_{0,0}^{2}} \frac{\partial h_{3}}{\partial \widetilde{v}}\right]} \\
& \frac{d v_{0,1}}{d \gamma}=\frac{\left(\frac{\partial h_{2}}{\partial v_{0,0}^{2}} \frac{\partial h_{3}}{\partial \gamma}-\frac{\partial h_{2}}{\partial \gamma} \frac{\partial h_{3}}{\partial v_{0,0}^{2}}\right) \frac{\partial h_{1}}{\partial \widetilde{v}}-\frac{\partial h_{1}}{\partial \gamma} \frac{\partial h_{2}}{\partial v_{0,0}^{2}} \frac{\partial h_{3}}{\partial \widetilde{v}}}{\left[\frac{\partial h_{1}}{\partial \widetilde{v}} \frac{\partial h_{2}}{\partial v_{0,1}} \frac{\partial h_{3}}{\partial v_{0,0}^{2}}-\frac{\partial h_{1}}{\partial \widetilde{v}} \frac{\partial h_{2}}{\partial v_{0,0}^{2}} \frac{\partial h_{3}}{\partial v_{0,1}}+\frac{\partial h_{1}}{\partial v_{0,1}} \frac{\partial h_{2}}{\partial v_{0,0}^{2}} \frac{\partial h_{3}}{\partial \widetilde{v}}\right]} \\
& \frac{d v_{0,0}^{2}}{d \gamma}=\frac{\left(\frac{\partial h_{2}}{\partial \gamma} \frac{\partial h_{3}}{\partial v_{0,1}}-\frac{\partial h_{2}}{\partial v_{0,1}} \frac{\partial h_{3}}{\partial \gamma}\right) \frac{\partial h_{1}}{\partial \widetilde{v}}+\left(\frac{\partial h_{1}}{\partial \gamma} \frac{\partial h_{2}}{\partial v_{0,1}}-\frac{\partial h_{1}}{\partial v_{0,1}} \frac{\partial h_{2}}{\partial \gamma}\right) \frac{\partial h_{3}}{\partial \widetilde{v}}}{\left[\frac{\partial h_{1}}{\partial \widetilde{v}} \frac{\partial h_{2}}{\partial v_{0,1}} \frac{\partial h_{3}}{\partial v_{0,0}^{2}}-\frac{\partial h_{1}}{\partial \widetilde{v}} \frac{\partial h_{2}}{\partial v_{0,0}^{2}} \frac{\partial h_{3}}{\partial v_{0,1}}+\frac{\partial h_{1}}{\partial v_{0,1}} \frac{\partial h_{2}}{\partial v_{0,0}^{2}} \frac{\partial h_{3}}{\partial \widetilde{v}}\right]} .
\end{aligned}
$$

Note that:

$$
\begin{aligned}
\frac{\partial h_{1}}{\partial \widetilde{v}} & =\left(\frac{[1-\delta(1-p)]}{\delta(1-p)}+\left[1-F\left(v_{0,1}\right)\right]\right)>0 \\
\frac{\partial h_{1}}{\partial v_{0,1}} & =-\left(\widetilde{v}-v_{0,1}\right) f\left(v_{0,1}\right)<0 \\
\frac{\partial h_{2}}{\partial v_{0,1}} & =\left(\frac{[1-\delta(1-p)]}{\delta(1-p)}+\left[1-F\left(v_{0,1}\right)\right]+\frac{p}{\delta(1-p)^{2}}\right)>0 \\
\frac{\partial h_{2}}{\partial v_{0,0}^{2}}=-\frac{p}{\delta(1-p)^{2}}<0 & -\frac{(1-\gamma)}{2}\left(\frac{[1-\delta(1-p)]}{\delta(1-p)}+\left[F\left(v_{0,1}\right)-F\left(v_{0,0}^{2}\right)\right]\right)<0, \\
\frac{\partial h_{3}}{\partial \widetilde{v}}= & -\left(\frac{\left[1-\delta(1-p)^{2}\right]}{\delta(1-p)^{2}}+\frac{(1-\gamma)}{2}\left(\widetilde{v}-v_{0,1}\right) f\left(v_{0,1}\right)\right)<0, \\
\frac{\partial h_{3}}{\partial v_{0,1}}= & \left(\frac{\left[1-2 p-\delta(1-p)^{2}\right]}{\delta(1-p)^{2}}+\left[1-F\left(v_{0,0}^{2}\right)\right]+\frac{(1-\gamma)}{2}\left(\widetilde{v}-v_{0,0}^{2}\right) f\left(v_{0,0}^{2}\right)\right)>0 . \\
\frac{\partial h_{3}}{\partial v_{0,0}^{2}}= &
\end{aligned}
$$

Hence, when $p=0$, the denominator in the comparative statics becomes:

$$
\begin{aligned}
& \frac{\partial h_{1}}{\partial \widetilde{v}} \frac{\partial h_{2}}{\partial v_{0,1}} \frac{\partial h_{3}}{\partial v_{0,0}^{2}}-\frac{\partial h_{1}}{\partial \widetilde{v}} \frac{\partial h_{2}}{\partial v_{0,0}^{2}} \frac{\partial h_{3}}{\partial v_{0,1}}+\frac{\partial h_{1}}{\partial v_{0,1}} \frac{\partial h_{2}}{\partial v_{0,0}^{2}} \frac{\partial h_{3}}{\partial \widetilde{v}} \\
= & \frac{\partial h_{1}}{\partial \widetilde{v}} \frac{\partial h_{2}}{\partial v_{0,1}} \frac{\partial h_{3}}{\partial v_{0,0}^{2}}>0 .
\end{aligned}
$$

Since the denominator is strictly positive for $p=0$, by continuity, it is strictly positive for $p$ close enough to 0 as well. Also,

$$
\frac{\partial h_{1}}{\partial \gamma}=\frac{\partial h_{2}}{\partial \gamma}=0, \text { and } \frac{\partial h_{3}}{\partial \gamma}=\frac{1}{2}\left(\frac{(1-\delta)}{\delta} \widetilde{v}+\int_{v_{0,0}^{2}}^{v_{0,1}}(\widetilde{v}-v) f(v) d v\right)>0
$$


Hence,

$$
\begin{aligned}
\operatorname{sign}\left(\frac{d \widetilde{v}}{d \gamma}\right) & =\operatorname{sign}\left(-\frac{\partial h_{1}}{\partial v_{0,1}} \frac{\partial h_{3}}{\partial \gamma} \frac{\partial h_{2}}{\partial v_{0,0}^{2}}\right) \leq 0 \\
\operatorname{sign}\left(\frac{d v_{0,1}}{d \gamma}\right) & =\operatorname{sign}\left(\frac{\partial h_{2}}{\partial v_{0,0}^{2}} \frac{\partial h_{3}}{\partial \gamma} \frac{\partial h_{1}}{\partial \widetilde{v}}\right) \leq 0, \\
\operatorname{sign}\left(\frac{d v_{0,0}^{2}}{d \gamma}\right) & =\operatorname{sign}\left(-\frac{\partial h_{2}}{\partial v_{0,1}} \frac{\partial h_{3}}{\partial \gamma} \frac{\partial h_{1}}{\partial \widetilde{v}}\right)<0 .
\end{aligned}
$$

Proof of Proposition 6. From the proof of Proposition 1, we know that $v_{0}$ is the solution to $g\left(v_{0}\right)=0$, where $g($.$) is an increasing function defined in (26)$.

From the proof of Proposition 4, we know that $v_{0,0}^{1}=\widetilde{v}>v_{0,1}$ for all $p \in(0,1)$ and hence we can rewrite 34 as follows:

$$
\begin{aligned}
\frac{[1-\delta(1-p)]}{\delta(1-p)} v_{0,0}^{1}= & \int_{v_{0,1}}^{\bar{v}}\left(v-v_{0,0}^{1}\right) f(v) d v \\
\text { or, } g\left(v_{0,0}^{1}\right)= & -\int_{v_{0,1}}^{v_{0,0}^{1}}\left(v_{0,0}^{1}-v\right) f(v) d v<0=g\left(v_{0}\right) .
\end{aligned}
$$

This implies that $v_{0,0}^{1}<v_{0}$.

Proof of Proposition 7. We adapt the system of equations for the two-project capacity version so that for a project of return $v$, the payoff of the joint venture is $(1+\gamma) v$, which is the sum of payoffs of the two firms when one firm selects. The definition of $W_{2}$ does not change and is given in (4). The revised equations for the other values are:

$$
\begin{aligned}
& W_{1}=\int_{w_{1}}^{\bar{v}}(1+\gamma) v f(v) d v+\left(1-F\left(w_{1}\right)\right) W_{2}+F\left(w_{1}\right) \delta\left(p W_{0}+(1-p) W_{1}\right), \\
& W_{0}=\int_{w_{0}}^{\bar{v}}(1+\gamma) v f(v) d v+\delta\left[1-F\left(w_{0}\right)\right]\left((1-p) W_{1}+p W_{0}\right)+\delta F\left(w_{0}\right) W_{0} .
\end{aligned}
$$

And for thresholds:

$$
\begin{aligned}
& (1+\gamma) w_{1}=\delta\left(p W_{0}+(1-p) W_{1}\right)-W_{2} \\
& (1+\gamma) w_{0}=\delta(1-p)\left(W_{0}-W_{1}\right)
\end{aligned}
$$


We now follow three steps to prove this proposition.

Step 1: We argue that the optimal project selection strategy of the two-projects capacity firm yields a value that is at least as large as the sum of equilibrium values of the two firms in the game, i.e., $W_{0} \geq 2 V_{0,0}$. The reason why this is true is that the two-projects capacity decision maker can mimic the selection behavior of the strategic firms by setting thresholds:

$$
w_{0}=v_{0,0}^{2} \text { and } w_{1}=v_{0,1} .
$$

With these thresholds, a project is implemented by the decision maker if and only if one of the firms would have selected the project in the game. It can be shown that:

$$
\left\{\begin{array}{c}
W_{1}=\left(V_{0,1}+V_{1,0}\right) \\
W_{0}=2 V_{0,0} \\
W_{2}=2 V_{1,1}
\end{array}\right.
$$

satisfies the system of equations (4), (38) and (39) that defines values for given thresholds in the two-projects capacity problem. Because the two-projects capacity decision maker can achieve at least $2 V_{0,0}$ in state 0 , it must be that in the optimal strategy, $W_{0} \geq 2 V_{0,0}$.

Step 2: We have shown in Proposition 4 that $v_{0,0}^{2}<v_{0,0}^{1}=\widetilde{v}$. This implies that:

$$
\int_{v_{0,0}^{2}}^{\bar{v}}\left(v-v_{0,0}^{2}\right) f(v) d v>\int_{v_{0,0}^{2}}^{\bar{v}}(v-\widetilde{v}) f(v) d v .
$$

We subtract $\delta V_{0,0}$ from both sides of (16), rearrange and substitute (13) and (14) to find that:

$$
(1-\delta) V_{0,0}=\int_{v_{0,0}^{2}}^{\bar{v}}\left(v-v_{0,0}^{2}\right) f(v) d v-\frac{(1-\gamma)}{2} \int_{v_{0,0}^{2}}^{\bar{v}}(v-\widetilde{v}) f(v) d v
$$

and hence we have:

$$
\begin{aligned}
(1-\delta) 2 V_{0,0} & =2 \int_{v_{0,0}^{2}}^{\bar{v}}\left(v-v_{0,0}^{2}\right) f(v) d v-(1-\gamma) \int_{v_{0,0}^{2}}^{\bar{v}}(v-\widetilde{v}) f(v) d v \\
& >2 \int_{v_{0,0}^{2}}^{\bar{v}}\left(v-v_{0,0}^{2}\right) f(v) d v-(1-\gamma) \int_{v_{0,0}^{2}}^{\bar{v}}\left(v-v_{0,0}^{2}\right) f(v) d v \\
& =(1+\gamma) \int_{v_{0,0}^{2}}^{\bar{v}}\left(v-v_{0,0}^{2}\right) f(v) d v .
\end{aligned}
$$


Suppose, by contradiction, that $w_{0} \geq v_{0,0}^{2}$. Then,

$$
(1-\delta) 2 V_{0,0}>(1+\gamma) \int_{v_{0,0}^{2}}^{\bar{v}}\left(v-v_{0,0}^{2}\right) f(v) d v \geq(1+\gamma) \int_{w_{0}}^{\bar{v}}\left(v-w_{0}\right) f(v) d v=(1-\delta) W_{0}
$$

Where the last equality is derived from (39) and (41). But we argued that $W_{0} \geq 2 V_{0,0}$, a contradiction! Hence, it must be that $w_{0}<v_{0,0}^{2}$.

Step 3: We argue that because $v_{0,0}^{2}>w_{0}$, it must follow that $v_{0,1}>w_{1}$. By contradiction, if it was the case that $v_{0,1} \leq w_{1}$, then using the definition of $g($.$) in (26)$ in the proof of Proposition 1, we have:

$$
\begin{aligned}
g\left(v_{0,1}\right) & \leq g\left(w_{1}\right) \text { because } g(.) \text { is increasing } \\
& \Rightarrow \frac{p\left(v_{0,0}^{2}-v_{0,1}\right)}{\delta(1-p)^{2}} \leq \frac{p\left(w_{0}-w_{1}\right)}{\delta(1-p)^{2}} \text { by }(35) \text { and }(33) \\
& \Rightarrow\left(v_{0,0}^{2}-v_{0,1}\right) \leq\left(w_{0}-w_{1}\right) \\
& \Rightarrow\left(v_{0,0}^{2}-w_{0}\right) \leq\left(v_{0,1}-w_{1}\right) \leq 0 \\
& \Rightarrow v_{0,0}^{2} \leq w_{0}, \text { a contradiction! }
\end{aligned}
$$

Hence, it must be that $v_{0,1}>w_{1}$.

Proof of Proposition 8. In state $(0,0)$, firm $B$ will select a rejected project if its value is $v>v_{0,0}^{B}$. Firm $A$ will select a project that would have been selected by firm $B$ if it were rejected by firm $A$, if $v>\widetilde{v}$. Firm $A$ will select a project that would have also been rejected by firm $B$ if it were rejected by firm $A$, if $v>\widetilde{\widetilde{v}}$. Therefore, firm $A$ selects if $v>\max \left\{v_{0,0}^{B}, \widetilde{v}\right\}$, or if $\widetilde{\widetilde{v}}<v<v_{0,0}^{B}$. If $v<\min \left\{v_{0,0}^{B}, \widetilde{\widetilde{v}}\right\}$, neither firm selects. Firm $A$ rejects and firm $B$ selects when $v$ is in the range $\left[v_{0,0}^{B}, \widetilde{v}\right)$.

Consider the case $p=0$ and $\gamma=0$. Specializing the system of dynamic equations, we obtain:

$$
V_{1,1}^{i}=V_{1,0}^{A}=V_{0,1}^{B}=0, V_{0,1}^{A}=V_{1,0}^{B}, v_{0,1}^{A}=v_{1,0}^{B}=\delta V_{0,1}^{A}
$$

Additionally, $v_{0,1}^{A}$ is given by the solution of the following:

$$
v_{0,1}^{A}=\frac{\delta}{1-\delta F\left(v_{0,1}^{A}\right)} \int_{v_{0,1}^{A}}^{\bar{v}} v f(v) d v
$$


In state $(0,0)$, thresholds satisfy:

$$
v_{0,0}^{B}=\delta V_{0,0}^{B}, \widetilde{v}=\delta V_{0,1}^{A}=v_{0,1}^{A} \text { and } \widetilde{\widetilde{v}}=\delta V_{0,0}^{A}
$$

We show first that in this case, the range in which firm $B$ selects is not empty. Suppose by contradiction that $v_{0,0}^{B} \geq \widetilde{v}=v_{0,1}^{A}$ so that firm $B$ never selects a project that was rejected by firm $A$. Then firm $A$ selects if $v>\min \left\{\widetilde{\widetilde{v}}, v_{0,0}^{B}\right\}:=v_{0,0}^{A}$. Hence,

$$
V_{0,0}^{A}=\int_{v_{0,0}^{A}}^{\bar{v}} v f(v) d v+F\left(v_{0,0}^{A}\right) \delta V_{0,0}^{A},
$$

implies that:

$$
V_{0,0}^{A}=\frac{1}{1-\delta F\left(v_{0,0}^{A}\right)} \int_{v_{0,0}^{A}}^{\bar{v}} v f(v) d v
$$

Also, we have:

$$
V_{0,0}^{B}=\int_{v_{0,0}^{A}}^{\bar{v}} \delta V_{1,0}^{B} f(v) d v+F\left(v_{0,0}^{A}\right) \delta V_{0,0}^{B},
$$

which implies that:

$$
V_{0,0}^{B}=\frac{\delta\left(1-F\left(v_{0,0}^{A}\right)\right)}{1-\delta F\left(v_{0,0}^{A}\right)} V_{0,1}^{A}<V_{0,1}^{A} \Rightarrow v_{0,0}^{B}<\widetilde{v}
$$

a contradiction! Hence, it must be that $v_{0,0}^{B}<\widetilde{v}$. This implies that the range for which firm $A$ rejects and firm $B$ selects is non-empty. Moreover, firm $A$ selects only in the range of high returns, $v>\widetilde{v}$. This is true because if $\min \left\{\widetilde{\widetilde{v}}, v_{0,0}^{B}\right\}=\widetilde{\widetilde{v}}$, then comparing (43) and 444, we can say that $\widetilde{\widetilde{v}}=v_{0,1}^{A}>v_{0,0}^{B}$, which is a contradiction.

\section{References}

[1] Bloch F. and N. Houy (2012). "Optimal Assignment of Durable Objects to Successive Agents," Economic Theory, 51(1), pp. 13-33.

[2] Burdett, K. and D. Mortensen (1998). "Wage Differentials, Employer Size, and Unemployment," International Economic Review, 39(2), pp. 257-273. 
[3] Cassiman, B. and M. Ueda (2006). "Optimal Project Rejection and New Firm Startups," Management Science, 52(2), pp 262-275.

[4] Daughety A. F. and J. F. Reinganum (2000). "On the Economics of Trials: Adversarial Process, Evidence, and Equilibrium Bias," Journal of Law, Economics, \& Organization, 16(2), pp. 365-394.

[5] Dixit, A. and R. Pindyck (1994). Investment Under Uncertainty. Princeton, NJ: Princeton University Press.

[6] Gilbert, R. J. (2006). "Competition and Innovation," Journal of Industrial Organization Education, 1(1), pp. 1-23.

[7] Gompers, P. and J. Lerner (2000). "The determinants of corporate venture capital success: Organizational structure, incentives, and complementarities," in Concentrated Corporate Ownership (pp. 17-54), University of Chicago Press.

[8] Hall, B. H. and J. Lerner (2010). "The Financing of R\&D and Innovation," in Hall, B. H. and N. Rosenberg (eds.) Handbook of the Economics of Innovation, Elsevier-North Holland.

[9] Harris, M. and A. Raviv (1996). "The Capital Budgeting Process: Incentives and Information," Journal of Finance, 51(4), pp. 1139-1174.

[10] Hassin R. and M. Haviv (2003). To Queue or not to Queue: Equilibrium Behavior in Queueing Systems. Kluwer Academic Publishers, Boston/Dordrecht/London.

[11] Hoppe H. (2000). "A Strategic Search Model of Technology Selection and Policy," in Michael R. Baye (ed.) Advances in Applied Microeconomics, 9: Industrial Organization, JAI Press, Greenwich, Conn, pp. 197-214.

[12] Kalai, E., Kamien, M. I. and M. Rubinovitch (1992). "Optimal Service Speeds in a Competitive Environment," Management Science, 38(8), pp. 1154-1163. 
[13] Kolchinsky, P. (2004). The entrepreneur's guide to biotech startup. Available at: http://www.evelexa.com/resources/EGBS4_Kolchinsky.pdf. Accessed on July 25, 2014.

[14] Lee, T. and L. Wilde (1980). "Market Structure and Innovation: A Reformulation." Quarterly Journal of Economics, 94(2), pp. 429-436.

[15] Lippman, S. and J. Mamer (1993). "Preemptive Innovation," Journal of Economic Theory, 61(1), pp. 104-119.

[16] Lippman, S. A and S. M. Ross (1971). "The Street Walker's Dilemma: A Job Shop Model," Journal of Applied Mathematics, 20(3), pp. 336-342.

[17] Loury G. C. (1979). "Market Structure and Innovation." Quarterly Journal of Economics, 93(3), pp. 395-410.

[18] McCall, J. J. (1970). "Economics of Information and Job Search." Quarterly Journal of Economics, 84(1), pp. 113-26.

[19] Mortensen, D. T. (1970). "A Theory of Wage and Employment Dynamics," in E. S. Phelps et al. (eds.) Microeconomic Foundations of Employment and Inflation Theory, New York: W. W. Norton, pp. 124-66.

[20] Mortensen, D. T. and C. A. Pissarides (1999). "New Developments in Models of Search in the Labour Market," in O. C. Ashenfelter and D. Card (eds.) Handbook of Labor Economics, 3(B), Elsevier, pp. 2567-2627.

[21] Nichols, N. (1994). "Scientific Management at Merck: An interview with CFO Judy Lewent," Harvard Business review, 72(1), pp. 88-99.

[22] Taylor, C. R. (1995). "Digging for Golden Carrots: An Analysis of Research Tournaments," American Economic Review, 85(4), pp. 872-890.

[23] Pissarides, C. A. (1985). "Short-run Equilibrium Dynamics of Unemployment Vacancies and Real Wages," American Economic Review, 75(4), pp. 676-690. 
[24] Postel-Vinay, F. and J. M. Robin (2002). "Equilibrium Wage Dispersion with Worker and Employer Heterogeneity," Econometrica, 70(6), pp. 2295-2350.

[25] Reinganum, J. F. (1982). "Strategic Search Theory," International Economic Review, 23(1), pp. 1-17.

[26] Reinganum, J. (1983a). "Nash Equilibrium Search for the Best Alternative," Journal of Economic Theory, 30(1), pp. 139-152.

[27] Reinganum, J. (1983b). "Uncertain Innovation and the Persistence of Monopoly," American Economic Review, 73(4), pp. 741-748.

[28] Sims, C. A. (2010). "Rational Inattention and Monetary Economics," in B. M. Friedman and M. Woodford (eds.) Handbook of Monetary Economics, 3, Elsevier, pp. 155-181.

[29] Thomas, C. D. (2012) "Strategic Experimentation with Congestion," available at: http://faculty.arts.ubc.ca/lhao/teaching/econ523/thomas12.pdf. Accessed on July 25, 2014.

[30] Zhang, G. (1997). "Moral Hazard in Corporate Investment and the Disciplinary Role of Voluntary Capital Rationing," Management Science, 43(6), pp. 737-750. 